Invited Paper, 14th Int'l. Conf. on the Application of Accelerators in Research and Industry, Nov. 6-9, 1996 University of North Texas, Denton, TX, Conference Proceedings Published by AIP Press, New York, J.L. Duggan and I.L. Morgan, ed., 1997, pp369-375.

\title{
LOW-ENERGY RADIOACTIVE BEAM EXPERIMENTS USING THE UM-UND SOLENOID RNB APPARATUS AT THE UND TANDEM: PAST, PRESENT AND FUTURE
}

\author{
F.D. Becchetti \\ Department of Physics, University of Michigan \\ Ann Arbor, Michigan 48109 USA \\ J.J. Kolata \\ Department of Physics, University of Notre Dame \\ Notre Dame, IN 46556 USA
}

\begin{abstract}
Approximately ten years ago (1987) one of the first operational low-energy radioactive nuclear beam (RNB) facilities was put into place at the University of Notre Dame (UND) as a joint project between the University of Michigan (UM) and UND. The key elements to the success of the project were the installation of a largebore 3.5 Tesla superconducting solenoid (supplied by UM) to collect and focus secondary radioactive beams, combined with an upgrade of the UND FN Tandem, the latter including the addition of a high-intensity sputter ion source. The resulting secondary beams $\left({ }^{8} \mathrm{Li},{ }^{6} \mathrm{He},{ }^{7} \mathrm{Be},{ }^{8} \mathrm{~B},{ }^{18} \mathrm{~F}^{m}, \ldots\right)$ are generally produced by selective, high-cross-section direct reactions. These beams are sufficiently intense (viz. $10^{4} / \mathrm{s}$ to $10^{8} / \mathrm{s}$ ) to permit measurement of many low-energy reaction cross sectons of interest to nuclear astrophysics, nuclear reaction theory, and high-isospin nuclear physics. A review of past and recent RNB data obtained with this apparatus will be presented together with plans for a major upgrade using a pair of $6 \mathrm{~T}$ solenoids ( M.Y. Lee et al. - this conference).
\end{abstract}

\section{INTRODUCTION}

The low-energy radioactive nuclear beam (RNB) facility operated at the University of Notre Dame (UND) FNtandem Van de Graaff as a joint project between the University of Michigan (UM) and UND was one of the first operational RNB facilities in the world (1987). Until recently (mid-1996), it still produced some of the most intense low-energy RNBs available, specifically beams of ${ }^{6} \mathrm{He},{ }^{8} \mathrm{Li},{ }^{7} \mathrm{Be},{ }^{8} \mathrm{~B},{ }^{18} \mathrm{~F},{ }^{18} \mathrm{~F}^{m}$ (and others) with intensities $>10^{4} / \mathrm{s}$, with some beams $\left({ }^{8} \mathrm{Li}\right)$ approaching $10^{9} / \mathrm{s}$. These relatively high RNB intensities are generally needed to measure cross sections relevant to nuclear astrophysics (and other nuclear phenomena) since unlike projectile break up or elastic scattering, the cross sections are small (viz. mb vs. b). Thus, the success of the facility required the development of several high-intensity RNBs and related high-efficiency detection devices and techniques.

We'll now briefly describe some of these and then summarize the RNB experiments done with the facility (up to mid-1996) together with some of the more important discoveries made. Finally, we'll outline plans for a new, upgraded facility which will utilize two large s.c. solenoid magnets (additional information is available at UM Website http://www.physics.lsa.umich.edu/twinsol).

\section{RNB PRODUCTION}

The key developments (1985-96) were as follows:

a) development and installation of a large air-core superconducting solenoid as the secondary RNB collection and focussing device (1987-89)

b) utilization of selective, high-cross-section direct- or compound-nuclear reactions for the RNB production reactions $(1987-)$

c) installation of a high-intensity SNICs-type sputter ion source and rotating production target (1990)

d) improvements in the FN tandem accelerator (accelerator tubes; vacuum; strippers; time-of-flight beam pulser and sweeper; etc)

Although a rotating target mount was designed, built and installed, radiation damage still remains a problem for certain production targets, and to this day often limits the amount of primary beam which can be used (by $\mathrm{x} 5$ to $\mathrm{x} 10)$. Most recently, a ${ }^{3} \mathrm{He}$ gas cell has been used for the efficient production of a ${ }^{8} \mathrm{~B}$ beam via the ${ }^{6} \mathrm{Li}\left({ }^{3} \mathrm{He}, \mathrm{n}\right){ }^{8} \mathrm{~B}$ reaction (Table I). This cell has Havar windows 2 microns thick and has been successfully run at 1 atm of ${ }^{3} \mathrm{He}$ for a 
week with ca. $1 \mu \mathrm{A}$ of $30 \mathrm{MeV}^{6} \mathrm{Li}$ primary beam. (It has recently been tested to 10 atms.) Many future experiments will utilize this cell or a similar one.

We generally select a direct nuclear reaction to form the RNB of interest via a specific nuclear state having a high production cross section ( viz. $>10 \mathrm{mb} / \mathrm{sr}$ at lab angles $\theta<10^{\circ}$ ). Additionally, the production reaction is done, if possible, on a high-melting-temperature target in reverse kinematics (heavy beam on a light target) so that one gains a large forward-angle enhancement from the c.m. to the lab system. Unlike fragmentation reactions, which are typically used at higher energies, the use of a more selective direct reaction is much more efficient in terms of the RNB yield for a given RNB energy spread (phase space). This is important for producing useable RNBs having a good energy resolution, as an example to resolve final nuclear states which typically require $\delta \mathrm{E}(\mathrm{FWHM}) \lesssim 1 \mathrm{MeV}$. Also, we have exploited production-reaction selectivity to produce short-lived, excited nuclear isomer beams, specifically ${ }^{18} \mathrm{~F}^{\mathrm{m}}\left(\mathrm{J}^{\pi}=5^{+} ; \mathrm{E}_{\mathrm{x}}=1.12 \mathrm{MeV} ; \mathrm{T}_{1 / 2}=163 \mathrm{nsec}\right)$. The mechanism for producing ${ }^{18} \mathrm{~F}^{\mathrm{m}}$ at low energies [via the ${ }^{12} \mathrm{C}\left({ }^{17} \mathrm{O},{ }^{18} \mathrm{~F}^{\mathrm{m}}\right)$ reaction] has also proved effective at higher energies (see Tables). Details of specific RNB production reactions and their yields may be found in the references given in Tables I and II.

After RNB production at the primary-beam target, it is then desirable to collect, separate and then refocus the selected RNB as efficiently as possible. Since, even with kinematic focussing the RNB production "cone" can be fairly large at low energies, the best device to refocus the beam is one with a large, axi-symmetric acceptance. Large, superconducting solenoids appear to be well-suited for this task ${ }^{1)}$ owing to their simple yet "fast" optics i.e. their good "f/\#" (the ratio of aperture to focal length) which is a measure of the collection efficiency.

We discovered, rather serendipitously, the advantages of using such devices as RNB collectors during a set of experiments done in 1984-86 at the ATLAS facility at Argonne National Laboratory (ANL). As part of a Ph.D. thesis project, a $3.5 \mathrm{~T}, 20 \mathrm{~cm}$ bore, $40 \mathrm{~cm}$ long air-core, superconducting solenoid (obtained surplus by UM from the DoE laser-fusion program) was installed and configured for use as a large solid angle, "zero-degree" reaction-product spectrometer ${ }^{1)}$. This concept was based on the work of Schapira et al. at IPN-Orsay who had used an iron-yoked s.c. solenoid for this purpose ${ }^{2}$.

In the ANL-ATLAS experiments, which used a ca. $100 \mathrm{MeV}{ }^{18} \mathrm{O}$ beam on various targets, a major limitation was pulse pile up at the solenoid focal-plane detector due to "unwanted" reaction products such as ${ }^{16,17} \mathrm{O},{ }^{19} \mathrm{~F}$, i.e. stable ions, as well as the radioactive ions (RNBs) ${ }^{15,19} \mathrm{O},{ }^{17,18,20} \mathrm{~F}$, where the latter were often at the $10^{2}$ to $10^{3} / \mathrm{s}$ level. At that point it was realized that the solenoid magnet could be utilized as a simple but effective RNB collector. It was therefore subsequently moved to UND for this purpose ${ }^{3)}$ as part of a joint UM-UND project (Fig. 1). Recent improvements at UND now permit operation to ca. $10 \mathrm{MV}$ terminal voltage with primary beams up to A $\sim 40$, with $\mu$ A's of intensity, with variable pulse width $(\delta \mathrm{t} \sim 1 \mathrm{nsec})$ and beam-pulse spacing.

In the course of operating the RNB apparatus, we've developed other axi-symmetric ion-optical systems ${ }^{4)}$ which we plan to utilize in future work. These include an $\overrightarrow{\mathrm{E}} \otimes \overrightarrow{\mathrm{B}}$ system using a radial electric field lens, and systems based on focussing and defocussing solenoids. In addition, funding from DoE and UM was obtained to build a large-bore $7 \mathrm{~T}$ system for use at $\mathrm{NSCL}^{5}$. A dual solenoid system ${ }^{6}$ ) which can utilize time-of-flight for improved RNB energy resolution was also developed.

\section{RNB REACTIONS STUDIED, 1987-1996}

A summary of the RNB reactions studied with the $3.5 \mathrm{~T}$ apparatus is given in Table I. Appropriate references for this table and related work are given in Table II. A number of these studies were the first of their type done with an RNB, and they revealed a number of important properties. Specifically, due to the nature of the unstable projectile RNB-induced nucleon transfer reactions and fusion-evaporation reactions are often highly exothermic $(\mathrm{Q}>0)$. Hence we find:

1) large cross sections to excited states, even at low energies (Fig. 2), due to

2) a favorable reaction "Q-window"; and hence

3) RNB n-tunneling at low energies is favored, and

4) very energetic neutrons and $\alpha$ particles can be produced in low-energy RNB fusion-evaporation (CN) reactions.

We also observe:

5) large BE2 $\Uparrow$ for certain RNB excitations,

6 ) with ${ }^{8} \mathrm{Li}$ elastic scattering and optical-model (OM) potentials similar to ${ }^{6} \mathrm{Li}$ and ${ }^{7} \mathrm{Li}$ elastic scattering (and $\mathrm{OMs}$ ) but ${ }^{6} \mathrm{He}$ is not similar to ${ }^{4} \mathrm{He}$ elastic scattering and its $\mathrm{OM}$ (Instead, ${ }^{6} \mathrm{He} \approx{ }^{6} \mathrm{Li},{ }^{7} \mathrm{Li}$ and ${ }^{8} \mathrm{Li}$ elastic scattering and OM-see Fig. 3).

Also,

7) measurements of many of the ${ }^{8} \mathrm{Li}$ S-factors needed for accurate input to Big-Bang nucleosynthesis and the "missing mass" problem were done including, recently, 
8) measurements of low-energy ${ }^{8} \mathrm{~B}$ break-up cross sections (Fig. 4) related to the solar neutrino problem (too few solar $\nu$ 's).

(While the latter measurements have helped to clarify both the "missing mass" and the solar neutrino problems, they unfortunately have not provided "solutions" to these problems.)

Finally, we have

9) demonstrated the feasibility of producing high-intensity isomeric, high-spin, excited RNBs for new types of nuclearreaction studies using " $\gamma$-tagged" RNBs.

\section{THE FUTURE}

The 3.5T RNB apparatus has been removed from its original beam line and will be re-installed elsewhere at UND. In its place a pair of $30 \mathrm{~cm}$ bore $6 \mathrm{~T}$ solenoids have been installed (funded by the US-NSF, UND and UM) and are presently being tested. This new system will provide a wider variety of RNBs including higher-mass, higher-energy (to $10 \mathrm{MeV} / \mathrm{u}$ ), and higher-purity beams. (The latter will be accomplished via. a radial $\overrightarrow{\mathrm{E}}$ electrode and/or absorber placed between the two magnets; see M. Lee et al., this conference).

We also intend to use fast timing of certain RNBs to provide an energy-compensated beam. This should permit highresolution (viz. $\delta \mathrm{E} \lesssim 100 \mathrm{keV}$ ) RNB measurements for Coulomb excitation, transfer reactions and other phenomena. The dual system will also permit low-background $\gamma-\gamma$ and $\gamma$-particle RNB measurements, low-energy RNB total reaction cross section measurements ${ }^{7)}$, and radioactive-ion trapping. We also plan to extend some of our previous measurements (Table I) to higher energies (and other nuclei) as well as pursue several new aspects of RNB research at both the nuclear and atomic levels.

\section{ACKNOWLEDGEMENTS}

This work has been funded by grants from the National Science Foundation, the University of Notre Dame, and the University of Michigan (Office of Vice-President for Research and the Department of Physics). We also gratefully acknowledge the post-doctoral scholars, Ph.D. students, and other UND and UM personnel who have participated in major aspects of this project, specifically W. Liu, R. Stern, R. Smith, J. Brown, D. Roberts, A. Morsad, K. Lamkin, L. Lamm, and E. Berners. 


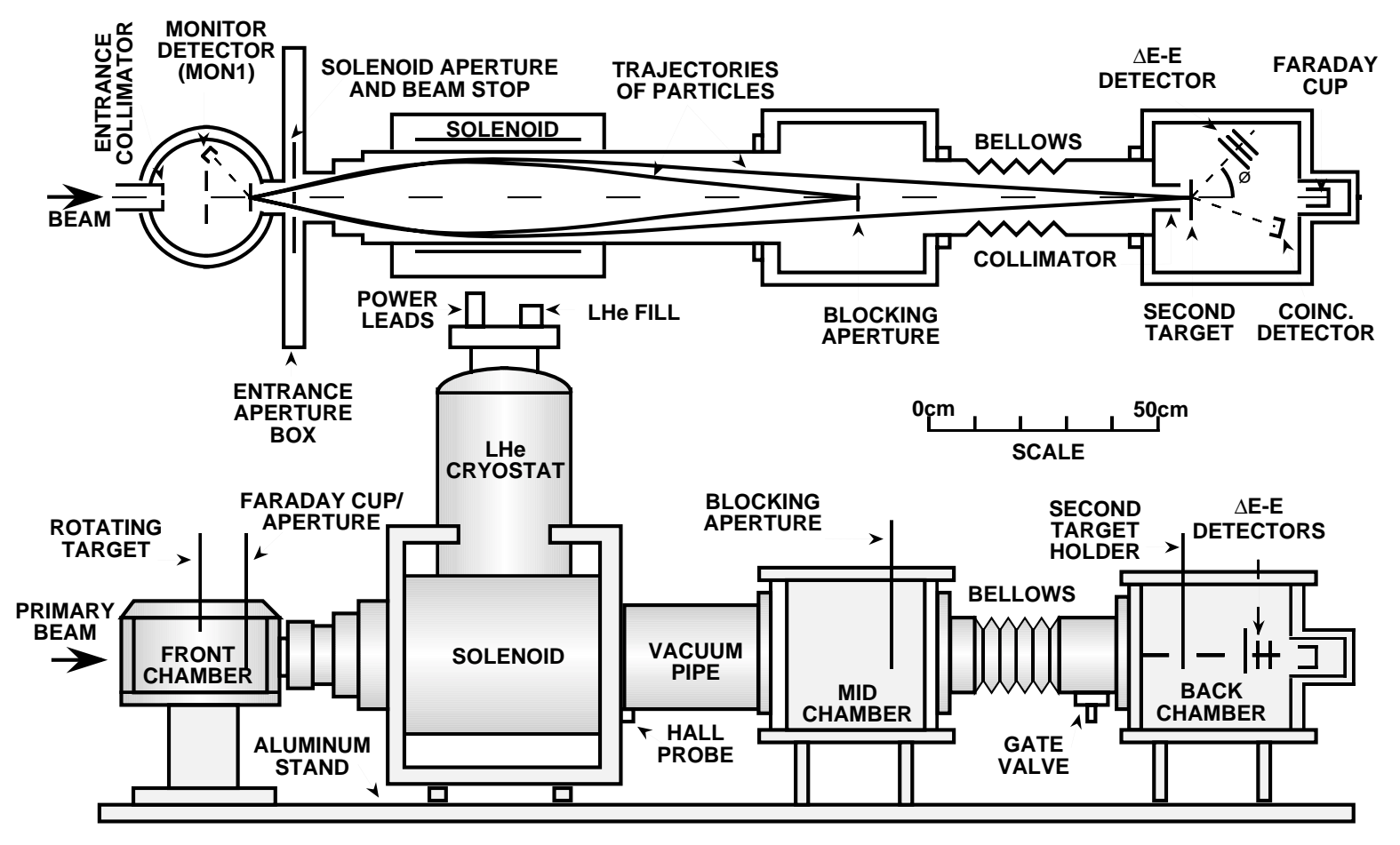

Figure 1. Top and side view of the UM-UND 3.5T RNB apparatus (1987-1996; from [Li89], Table II)

\section{REFERENCES}

1. See $[\mathrm{St} 87 \mathrm{a}, \mathrm{b}]$ and $[\mathrm{StC} 87]$ in Table II

2. J.P Schapira, S. Gales, and H. Laurent, Orsay Report IPNO-PhN-7921 (1979); J.P. Schapira, F. Azaiea, S. Fortier, S. Gales, E. Hourani, J. Kumpulainen, and J.M. Maison, Nucl. Instrum. Meth. 224, 337 (1984).

3. See [St87a,b,c], [StC87], [BeC88], [Ko89], and

[RNB1,2,3,4] in Table II

4. See [Li86], [Li89], [O'DC94] and [O'D94] in Table I

5. F.D. Becchetti, J. Bajema, J.A. Brown, F. Brunner, H. Griffin, J.W. Jänecke, T.W. O'Donnell, R.S. Raymond, D.A. Roberts, R.S. Tickle, R.M. Ronningen, H. Laumer, N. Orr, A. Zeller, and R.E. Warner, Nucl. Instrum. Meth. B79, 326 (1993).

6. See M.Y. Lee et al. [BAPS 41, 1028 (1996) and this conference] and [Be96b] in Table II.

7. D.A. Roberts, et al., Nucl. Phys. A588, 247c (1995); R.E. Warner, et al., Phys. Rev. C52, R1166 (1995) and Phys. Rev $C$ (1996), in press. 


\section{TABLE I: RNB Reactions Studied, 1987-1996}

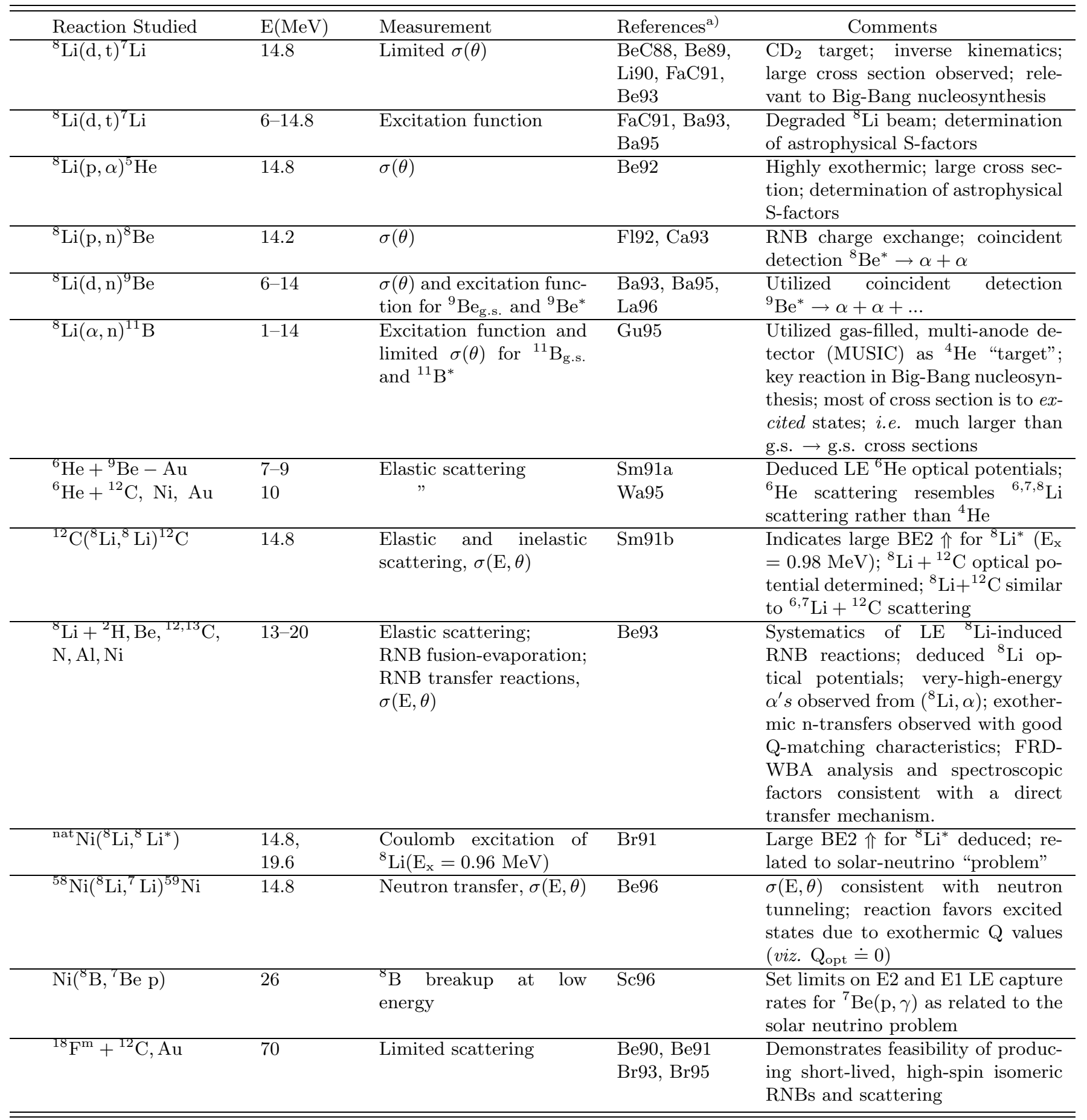

${ }^{a)}$ See Table II; early versions of most work are presented in [RNB1, 2, 3, 4] of Table II 
TABLE II: Bibliography for TABLE I (and Related References)

[Li86] "Focusing of Multiply-Charged Energetic Ions Using Solenoidal B and Radial E Fields," W.Z. Liu, F.D. Becchetti, and R. Stern, Rev. Sci. Instrum. 58 (1986) 220.

[St87a] "Tests of a Large Air-core Superconducting Solenoid Reaction Product Spectrometer," R.L. Stern, F.D. Becchetti, T. Casey, J.W. Jänecke, P.M. Lister, W.Z. Liu, D.G. Kovar, R.V.F. Janssens, M.F. Vineyard, W.R. Phillips and J. Kolata, Rev. Sci. Instrum. 58 (1987) 1682.

[Ko89] "A Radioactive Beam Facility using a Large Superconducting Solenoid," J.J. Kolata, A. Morsad, X.J. Kong, R. Warner, F.D. Becchetti, W.Z. Liu, D.A. Roberts, and J.W. Jänecke, Nucl. Instrum. Meth. B40/41 (1989) 503.

[Be89] "Measurements of Discrete Nuclear Reactions Induced by a Radioactive ${ }^{8}$ Li Beam," F.D. Becchetti, W.Z. Liu, D.A. Roberts, J.W. Jänecke, J.J. Kolata, A. Morsad, X.J. Kong, and R.E. Warner, Phys. Rev. C 40 (1989) R1104.

[Li89] "Large-aperture, Axially-symmetric Ion-optical Lens Systems Using New Types of Electrostatic and Magnetic Elements," W.Z. Liu and F.D. Becchetti, Rev. Sci. Instrum. 60 (1989) 1228.

[Sm90] "Production and Use of Radioactive ${ }^{7}$ Be Beams," R. J. Smith, J. J. Kolata, K. Lamkin, A. Morsad, K. Ashktorab, F. D. Becchetti, J. Brown, J. W. Jänecke, W. Z. Liu and D. A. Roberts, Nucl. Instrum. Methods A 294 (1990) 26.

[Be90] "Production of an Isomeric, Excited Radioactive Nuclear Beam," F. D. Becchetti, K. Ashktorab, J. A. Brown, J. W. Jänecke, D. A. Roberts, J. van Klinken, W. Z. Liu, J. J. Kolata, K. Lamkin, R. J. Smith and R. E. Warner, Phys. Rev. C 42 (1990) R801.

[Sm91a] "Scattering of ${ }^{6} \mathrm{He}$ from ${ }^{197} \mathrm{Au},{ }^{n a t} \mathrm{Ti},{ }^{27} \mathrm{Al},{ }^{n a t} \mathrm{C}$ and ${ }^{9} \mathrm{Be}$ at $\mathrm{E}=8-9 \mathrm{MeV}$," R.J. Smith, J. J. Kolata, K. Lamkin, A. Morsad, K. Ashktorab, F. D. Becchetti, J. B. Brown, J. W. Jänecke, W. Z. Liu and D. A. Roberts, Phys. Rev. C 43 (1991) 761.

[Be91] "Production and use of ${ }^{6} \mathrm{He},{ }^{7} \mathrm{Be},{ }^{8} \mathrm{Li},{ }^{12} \mathrm{~B}$ and Metastable Nuclear Beams,"F. D. Becchetti, J. A. Brown, K. Ashktorab, J. W. Jänecke, W. Z. Liu, D. A. Roberts, R. J. Smith, J. J. Kolata, K. Lamkin, A. Morsad and R. E. Warner, Nucl. Instrum. Methods B 56/57 (1991) 554.

[Sm91b] "Elastic and Inelastic Scattering of ${ }^{8} \mathrm{Li}$ from ${ }^{12} \mathrm{C}, "$ R.J. Smith, J. J. Kolata, K. Lamkin, A. Morsad, F. D. Becchetti, J. A. Brown, W. Z. Liu, J. W. Jänecke, D. A. Roberts and R. E. Warner, Phys. Rev. C 43 (1991) 2346.

[Br91] "Coulomb Excitation of ${ }^{8} \mathrm{Li}$," J. A. Brown, F. D. Becchetti, J. W. Jänecke, K. Ashktorab, D. A. Roberts,J. J. Kolata, R.J. Smith, K. Lamkin, and R. E. Warner, Phys. Rev. Lett. 66 (1991) 2452.

[Be92] "The Reaction Rates for ${ }^{8} \operatorname{Li}(p, \alpha)$ and ${ }^{8} \operatorname{Li}(p, n \alpha)$ and their Effect on Primordial Nucleosynthesis," F.D. Becchetti, J.A. Brown, W.Z. Liu, J.W. Jänecke, D.A. Roberts, J.J. Kolata, R.J. Smith, K. Lamkin, A. Morsad, R.E. Warner, R.N. Boyd, and J.D. Kalen, Nucl. Phys. A 550 (1992) 507.

[F192] "Applications of Kinematics to Nuclear Reactions Using Radioactive Ion Beams," N.R. Fletcher, Nucl. Instrum. and Meth. in Phys. Res. A 316 (1992) 143.

[Ca93] "Cross Sections for the Primordial Reaction ${ }^{8} \mathrm{Li}(\mathrm{p}, \mathrm{n})^{8} \mathrm{Be}(\mathrm{g} . \mathrm{s}$.$) at \mathrm{E}_{\text {c.m. }}=1.5 \mathrm{MeV}$, D.D. Caussyn, N.R. Fletcher, K.W. Kemper, E.E. Towers, J.J. Kolata, K.L. Lamkin, R.J. Smith, F.D. Becchetti, J.A. Brown, J.W. Jänecke, D.A. Roberts and .L. Gay, Phys. Rev. C 47 (1993) 387.

[Be93] "Systematics of ${ }^{8} \mathrm{Li}-$ Induced Radioactive Beam Reactions: $\mathrm{E}=13-20 \mathrm{MeV}$," F.D. Becchetti, W.Z. Liu, K. Ashktorab, J.F. Bajema, J.A. Brown, J.W. Jänecke, D.A. Roberts, J.J. Kolata, K.L. Lamkin, A. Morsad, R.J. Smith, and X.J. Kong, Phys. Rev. C 48 (1993) 308.

[Ba93] "2 H Induced Reactions on ${ }^{8} \mathrm{Li}$ and Primordial Nucleosynthesis," M.J. Balbes, M.M. Farrell, R.N. Boyd, X. Gu, M. Hencheck, J.D. Kalen, C. Mitchell, J.J. Kolata, K. Lamkin, R. Smith, R. Tighe, K. Ashktorab, F.D. Becchetti, J.B. Brown, D.A. Roberts, T.-F. Wang, D. Humphreys, G. Vourvopoulos, and M.S. Islam, Phys. Rev. Lett. 71 (1993) 3931. 
[O'D94] "Mass Separator Using a Large Solenoid "Lens" with Time of Flight, and Position-Sensitive Detectors," T.W. O'Donnell, E. Aldredge, F.D. Becchetti, J.A. Brown, P. Conlan, J. Jänecke, R.S. Raymond, D.A. Roberts, R.S. Tickle, H.C. Griffin, J. Staynoff, and R. Ronningen, Nucl. Instrum. Meth. A 353 (1994) 215.

[Ba95] "Cross Sections and Reaction Rates of $d+{ }^{8} L i$ Reactions Involved in Big Bang Nucleosynthesis," M.J. Balbes, M.M. Farrell, R.N. Boyd, X. Gu, M. Hencheck, J.D. Kalen, C.A. Mitchell, J.J. Kolata, K. Lamkin, R. Smith, R. Tighe, K. Ashktorab, F.D. Becchetti, J. Brown, D. Roberts, T.-F. Wang, D. Humphreys, G. Vourvopoulos, and M.S. Islam, Nucl. Phys. A 584 (1995) 315.

[Br95] "Proton Scattering from an Excited Nucleus $\left({ }^{18} F^{m}, J^{\pi}=5^{+}, E_{x}=1.1 \mathrm{MeV}\right)$ Using a $\gamma$-Ray Tagged Secondary Isomeric Nuclear Beam," J. Brown, F.D. Becchetti, J. Jänecke, D.A. Roberts, D.W. Litzenberg, T.W. O’Donnell, R.E. Warner, N.A. Orr, and R.M. Ronningen, Phys. Rev. C 51 (1995) 1312.

[Gu95] "The ${ }^{8} \operatorname{Li}(\alpha, n)^{11} B$ Reaction and Primordial Nucleosynthesis," X. Gu, R.N. Boyd, M.M. Farrell, J.D. Kalen, C.A. Mitchell, J.J. Kolata, K. Lamkin, K. Ashktorab, F.D. Becchetti, J. Brown, D. Roberts, K. Kimura, I. Tanihata, and K. Yoshida, Phys. Lett. B 343 (1995) 31.

[Wa95] "Elastic Scattering of $10 \mathrm{MeV}^{6} \mathrm{He}$ from ${ }^{12} \mathrm{C}$, nat $N i$, and ${ }^{197} \mathrm{Au}$," R.E. Warner, F.D. Becchetti, J.W. Jänecke, D.A. Roberts, D. Butts, C.L. Carpenter, J.M. Fetter, A. Muthukrishnan, J.J. Kolata, M. Belbot, K. Lamkin, M. Zahar, A. Galonsky, K. Ieki, and P. Zecher, Phys. Rev. C 51 (1995) 178.

[Be96] "Quasi-elastic Neutron Transfer from a Low-Energy Radioactive-Beam: ${ }^{8} \mathrm{Li}+{ }^{58} \mathrm{Ni}, E\left({ }^{8} \mathrm{Li}\right)=19.6 \mathrm{MeV}, "$ F.D. Becchetti, J.F. Bajema, K. Ashktorab, J.A. Brown, J.W. Jänecke, D.A. Roberts, J.J. Kolata, K. Lamkin, R.J. Smith, and R.E. Warner, in [RNB3] (submitted to Phys. Rev. C).

[Sc96] "Sub-Coulomb Dissociation of ${ }^{8}$ B," J. von Schwarzenberg, J.J. Kolata, D. Peterson, P. Santi, M. Belbot, and J.D. Hinnefeld, Phys. Rev. C 53 (1996) R2598.

\section{Conference Proceedings-Invited and Contributed Papers (1987-96)}

[StC87] "Test of A Large Air-core Superconducting Solenoid as a Nuclear Reaction Product Spectrometer and Radioactive Beam System," R.L. Stern, F.D. Becchetti, T. Casey, J.W. Jänecke, P.M. Lister, W.Z. Liu, D.G. Kovar, R.V.F. Janssens and J.J. Kolata, 5th International Conference on Nuclei Far From Stability, Rosseau Lake, Ontario, Canada (September 14-19, 1987), p. N7.

[BeC88] "A Radioactive Beam Facility Using a Large Superconducting Solenoid," F. Becchetti et al., International Symposium on Heavy Ion Physics and Nuclear Astrophysical Problems, Tokyo, Japan (July 1988).

[RNB1] Radioactive Nuclear Beams, The First International Conference Berkeley, CA (October 1989), edited by W.D. Myers, J.M. Nitschke, and E.B. Norman, World Scientific (Singapore 1989).

[FaC91] "Study of Deuteron Induced Reactions on ${ }^{8} \mathrm{Li}$ of Interest to Primordial Nucleosynthesis", M.M. Farrell et al., Int'l. Conf. on Unstable Nuclei in Astrophysics (Tokyo, June 1991).

[RNB2] Proc. Second International Conf. on Radioactive Nuclear Beams, Th. Delbar ed., Lovain-la-Nauve, Belgium 1991; Adam Hilger (Bristol 1992).

[RNB3] Proc. Third International Conference on Radioactive Nuclear Beams, Michigan State Universitiy, eds. D. Morrisey et al., Michigan State University, East Lansing, MI, 24-27 May 1993; Editions Frontieres (Gif-surYvette Cedex, France 1993).

[O'DC94] "Mass Separator Using a Large Solenoid "Lens" with Time of Flight, and Position-Sensitive Detectors," T.W. O’Donnell, E. Aldredge, F.D. Becchetti, J.A. Brown, P. Conlan, J. Jänecke, R.S. Raymond, D.A. Roberts, R.S. Tickle, H.C. Griffin, J. Staynoff, and R. Ronningen, Proc. 1994 Symp. on Radiation Measurements and Applications, Ann Arbor, MI; Nucl. Instrum. Meth. A 353 (1994) 215.

[BeC96] "TwinSol: A Dual Superconducting Air-core Solenoid Apparatus for the Production and Utilization of Radioactive Nuclear Beams," F.D. Becchetti, M.Y. Lee, T.W. O'Donnell, D.A. Roberts, J.J. Kolata, and M. Wiescher, Proceedings Fourth International Conference on Radioactive Nuclear Beams, Omiya, Japan (June 3-7, 1996).

[RNB4] Proc. Fourth International Conference on Radioactive Nuclear Beams, Omiya, Japan (June 3-7, 1996), in press. 


\section{Theses}

[St87b] "Design and Utilization of an Air-core Superconducting-Solenoid Nuclear-Reaction-Product Spectrometer," R.L. Stern, Ph.D. Thesis, University of Michigan, UM-NP-RS-87-1 (1987). [Includes research done at ANLATLAS (Argonne, IL)].

[Li90] "Production and Use of Radioactive Ion Beams for Measurements of Nuclear Reactions," W.Z. Liu, Ph.D. Thesis, University of Michigan (1990).

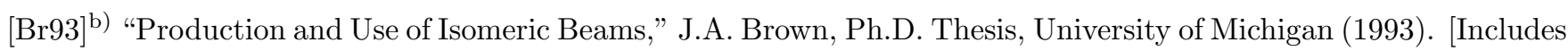
research done at the NSCL (MSU-E. Lansing, MI)].

[La96] "The Study of the $d+{ }^{8}$ Li Reaction at Astrophysical Energies," K. Lamkin, Ph.D. Thesis, University of Notre Dame (1996).

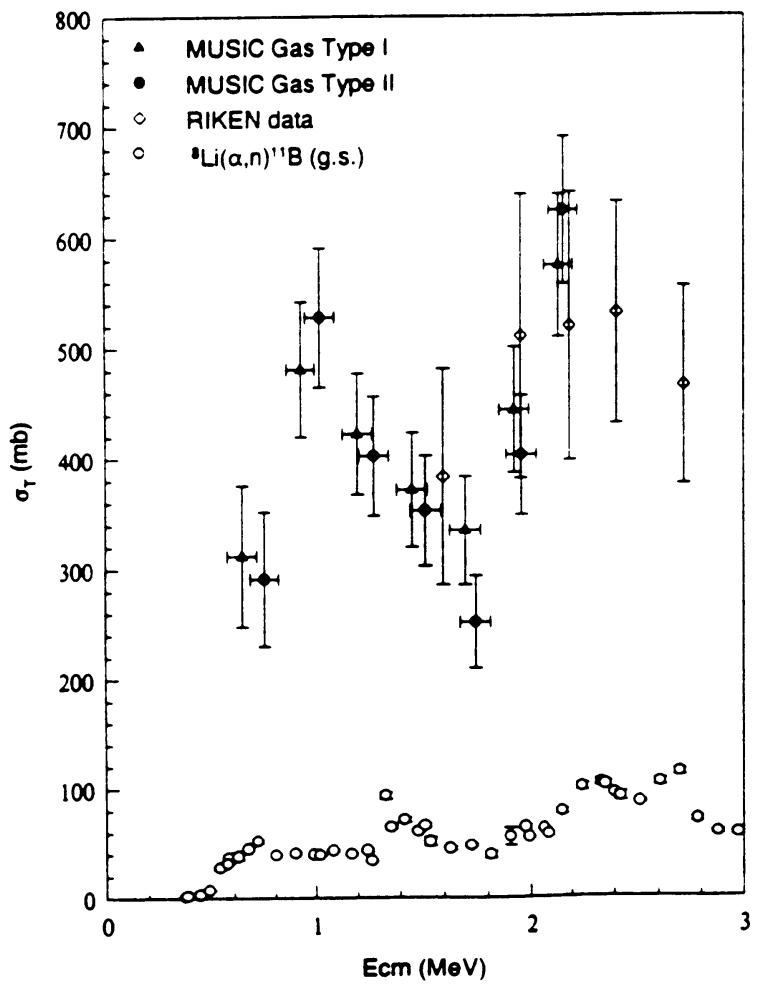

Figure 2. Cross section for ${ }^{8} \mathrm{Li}(\alpha, \mathrm{n}){ }^{11} \mathrm{~B}^{*}+{ }^{11} \mathrm{~B}_{\text {g.s. }}$ (top) compared with ${ }^{8} \mathrm{Li}(\alpha, \mathrm{n}){ }^{11} \mathrm{~B}_{\text {g.s. }}$ (from [Gu95], Table II). 


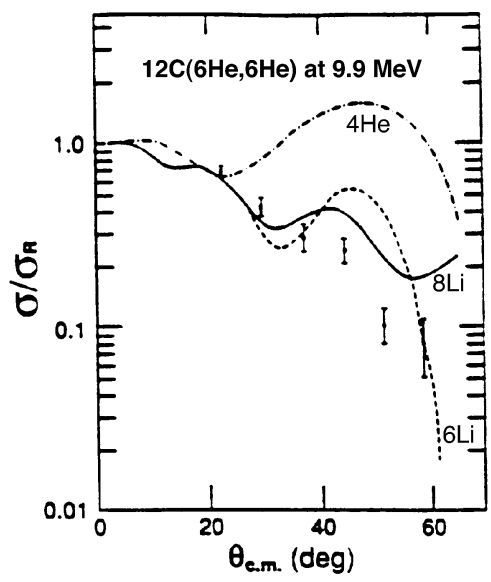

Figure 3. Elastic scattering of $10 \mathrm{MeV}{ }^{6} \mathrm{He}$ from ${ }^{12} \mathrm{C}$ compared with ${ }^{4} \mathrm{He},{ }^{6} \mathrm{Li}$ and ${ }^{8} \mathrm{Li}$ OM predictions ([Wa95], Table II).

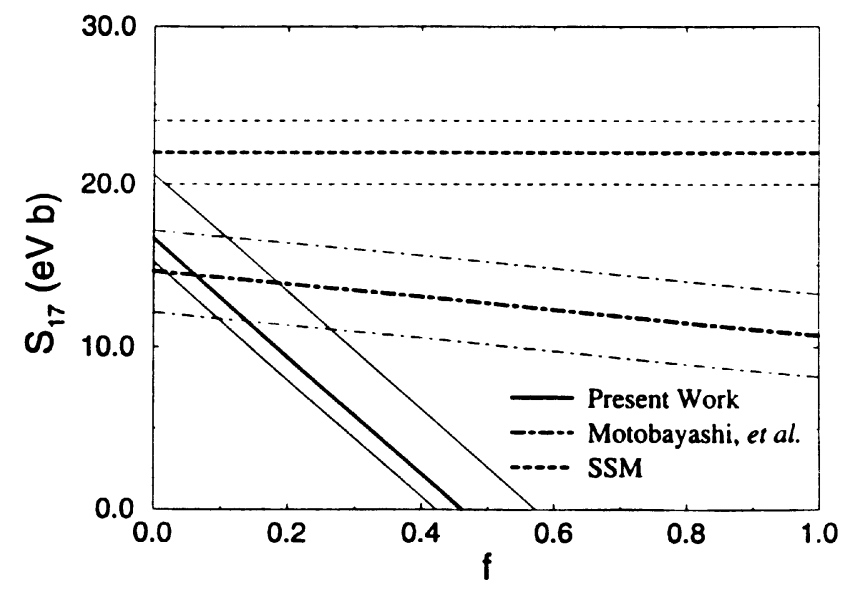

Figure 4. Plot of the ${ }^{7} \operatorname{Be}(\mathrm{p}, \gamma)$ astrophysical $\mathrm{S}_{17}$ factor extrapolated to solar energies, as a function of the $E 2$ component of the breakup yield, for the recent UND work ([Sc96], Table II), the data of T. Motobayashi et al., [Phys. Rev. Lett. 73, 2680 (1994)] and the standard solar model. 
Table A

\section{Low-Energy Radioactive Beams Produced}

\begin{tabular}{|c|c|c|c|c|c|c|}
\hline \multicolumn{3}{|c|}{$\begin{array}{l}\mathrm{E}(\mathrm{MeV}) \\
\text { and FWHM } \\
\qquad(\mathrm{MeV})\end{array}$} & \multirow{2}{*}{$\begin{array}{l}\text { Production } \\
\text { Reaction } \\
{ }^{9} \mathrm{Be}\left({ }^{7} \mathrm{Li},{ }^{8} \mathrm{Li}\right)\end{array}$} & \multirow{2}{*}{$\begin{array}{l}\text { Production } \\
\text { Target } \\
\mathrm{XXmg} / \mathrm{cm}^{2} \\
{ }_{\text {nat }} \mathrm{Be}\end{array}$} & \multirow[t]{2}{*}{$\begin{array}{l}\mathrm{RNB}^{a)} \\
\text { Intensity }^{a)}\end{array}$} & \multirow{2}{*}{$\begin{array}{l}\text { Comments } \\
\text { Rotating target; intensity limited by radi- } \\
\text { ation damage to target. }\end{array}$} \\
\hline${ }^{8} \mathrm{Li}$ & 14.5 & 450 & & & & \\
\hline & 19.X & 600 & $"$ & $" n$ & & " \\
\hline${ }^{6} \mathrm{He}$ & ca.10 & 400 & ${ }^{9} \mathrm{Be}\left({ }^{7} \mathrm{Li},{ }^{6} \mathrm{He}\right)$ & $" n$ & & $\begin{array}{l}\text { RNB Purity varies with collimation (see } \\
\text { Refs.) }\end{array}$ \\
\hline \multicolumn{7}{|l|}{${ }^{7} \mathrm{Be}$} \\
\hline${ }^{8} \mathrm{~B}$ & & & ${ }^{6} \mathrm{Li}\left({ }^{3} \mathrm{He}, \mathrm{n}\right)$ & $\begin{array}{l}{ }^{3} \mathrm{He} \text { gas cell } \\
(\mathrm{P}=1 \mathrm{~atm})\end{array}$ & & $\begin{array}{l}{ }^{1} \mathrm{H}_{2} \text { gas cell; } \mathrm{P}=1 \text { atm; gas cell recently } \\
\text { modified to run } \mathrm{P}=10 \text { atms }\end{array}$ \\
\hline${ }^{10} \mathrm{~B}$ & & & & & & $\begin{array}{l}\text { Fusion reaction }(\mathrm{CN}) \text { with large cross } \\
\text { section }\end{array}$ \\
\hline${ }^{18} \mathrm{~F}^{m}$ & 80 & & $\begin{array}{l}\mathrm{XX} \mathrm{mg} / \mathrm{cm}^{2} \\
\text { carbon foil } \\
{ }^{12} \mathrm{C}\left({ }^{17} \mathrm{O},{ }^{18} \mathrm{~F}\right)\end{array}$ & & & $\begin{array}{l}\text { Reaction preferentially populates the } J^{\pi}= \\
5^{+} \text {isomer at } \mathrm{E}_{\mathrm{x}}=1.12 \mathrm{MeV} \text { in }{ }^{18} \mathrm{~F} \text {; method } \\
\text { used later at NSCL to produce high-purity } \\
\text { HE isomeric }{ }^{18} \mathrm{~F}^{m} \text { (see Refs.) }\end{array}$ \\
\hline
\end{tabular}

$\overline{a)}$ Per particle microamp of production beam. (The latter is typical intensity for a production. Beam without beams pulsing.) 